\title{
Análisis Comparativo Del Posicionamiento GNSS Utilizando Receptor De Bajo Costo U-Blox De Doble Frecuencia Para Aplicaciones Topógrafo-Geodésicas
}

\author{
Rosendo Romero-Andrade, \\ Juan L. Cabanillas-Zavala,
}

Facultad de Ciencias de la Tierra y el Espacio, Posgrado en Ciencias de la Información, Universidad Autónoma de Sinaloa

Daniel Hernández-Andrade,

Facultad de Ingeniería, Colegio de Ingeniería Topográfica y Geodésica, Benemérita Universidad Autónoma de Puebla.

Manuel E. Trejo-Soto, Sergio A. Monjardin-Armenta,

Facultad de Ciencias de la Tierra y el Espacio, Posgrado en Ciencias de la Información, Universidad Autónoma de Sinaloa

Doi:10.19044/esj.2020.v16n27p289 URL:http://dx.doi.org/10.19044/esj.2020.v16n27p289

\section{Resumen}

Se evaluó y comparó estadísticamente el posicionamiento obtenido a través del receptor de bajo costo U-blox ZED-F9P de nueva generación con un receptor geodésico, realizando observaciones GNSS sobre un vértice geodésico mediante del método de Posicionamiento Puntual Preciso y relativo estático, con una distancia de $33 \mathrm{~km}$ a la estación de referencia. Esto, con la finalidad de probar la factibilidad de utilizar receptores de bajo costo de gama similares en trabajos topográficos-geodésicos. Para ello, se consideran cuatro escenarios; en el primer escenario, se aplicó la técnica relativo estático con el equipo de bajo costo, en el segundo escenario se procesó con un receptor geodésico en modo relativo estático; ambos mediante un software comercial. Para el tercer y cuarto escenario, se procesó modo Posicionamiento Puntual Preciso con el software RTKLIB. Los resultados muestran que para la técnica Posicionamiento Puntal Preciso la precisión lograda de $1 \mathrm{~cm}$ por el equipo de bajo costo es apta para realizar trabajos geodésicos. En el método relativo estático, la precisión lograda de $7 \mathrm{~mm}$ indica que es posible utilizar el equipo de bajo costo para trabajos topógrafos-geodésicos de alta precisión considerando una línea base $\leq 33 \mathrm{~km}$, esto, según la normatividad del Instituto Nacional de Estadística y Geografía. 
Palabras Clave: GNSS, U-Blox ZED-F9P, Posicionamiento Puntual Preciso, Relativo Estático

\title{
Comparative Analysis Of The GNSS Positioning By Using U-Blox Dual-Frequency Low-Cost Receiver For Topographic-Geodetic Applications
}

\section{Rosendo Romero-Andrade, Juan L. Cabanillas-Zavala,}

Facultad de Ciencias de la Tierra y el Espacio, Posgrado en Ciencias de la Información, Universidad Autónoma de Sinaloa

Daniel Hernández-Andrade,

Facultad de Ingeniería, Colegio de Ingeniería Topográfica y Geodésica, Benemérita Universidad Autónoma de Puebla.

\section{Manuel E. Trejo-Soto, Sergio A. Monjardin-Armenta,}

Facultad de Ciencias de la Tierra y el Espacio, Posgrado en Ciencias de la Información, Universidad Autónoma de Sinaloa

\begin{abstract}
The new generation, low-cost U-blox ZED-F9P receiver was evaluated and statistically compared by GNSS observations on a geodesic monument, through both Precise Point Positioning and Static relative positioning techniques with a distance of $33 \mathrm{~km}$ from the references station. This was done with the purpose of checking the use feasibility of the low-cost receiver of similar gamma in topographic-geodesic works. To that end, four scenarios were considered: in the first scenario, the static relative positioning with the low-cost equipment was applied; in the second scenario, the static relative positioning with a geodetic receiver was applied. Both scenarios were processed with commercial software. The third and fourth scenarios were processed with Precise Point Positioning techniques through the RTKLIB software. The results show that Precise Point Positioning techniques get a precision of $1 \mathrm{~cm}$ through the use of low-cost equipment which is suitable to apply in geodetic works. In the static relative method, the precision obtained is $7 \mathrm{~mm}$, indicating the possibility of using the low-cost equipment in both survey and geodetic high precision works, considering a line base $\leq 30 \mathrm{Km}$, according to the Instituto Nacional de Estadística y Geografía normative.
\end{abstract}


Keywords: GNSS, U-Blox ZED-F9P, Precise Point Positioning, Static Relative Positioning

\section{Introducción}

Hoy en día con el avance de la geodesia, específicamente con los Sistemas de Navegación Global por Satélite (GNSS), ha sido posible desarrollar nuevas metodologías y estudios, los cuales se avocan a la mejora continua de la precisión de posicionamiento sobre un punto sobre la superficie de la Tierra, por ejemplo: análisis ionosférico como precursor sísmico (Sharma et al. 2018), estudios de deformación de la corteza (Chen et al. 2014), meteorología (Cabral-Cano et al. 2018), por citar algunos. Sin embargo, este tipo de estudios requieren de receptores con características técnicas que los convierten en receptores geodésicos o científicos (con un elevado precio), logrando alcanzar precisiones al nivel milimétrico en función del tratamiento de la información generada.

Por otro lado, debido a los altos precios en los años noventa, surgen como alternativa los receptores de bajo costo (low-cost) (Tsakiri et al. 2017), los cuales, en un principio, lograban precisiones de metros, siendo usados para aplicaciones de mapeo y navegación terrestre (Zamora-Maciel et al. 2020).

Con base en lo anterior, los equipos de bajo costo son también llamados de alta sensibilidad, que alcanzan en promedio de -160 dB (Tsakiri et al. 2018) a diferencia de los receptores geodésicos que utiliza en promedio $-128.5 \mathrm{~dB}$ (Zamora-Maciel et al. 2020); lo cual, de acuerdo con Romero-Andrade et al. (2019); Zamora-Maciel et al. (2020) afecta en gran medida el posicionamiento, ya que recibe señales degradadas por objetos cercanos al receptor logrando alcanzar $10 \mathrm{~m}$, debido al efecto de multitrayectoria (Romero-Andrade et al. 2019).

Estrictamente para la geodesia, los equipos de bajo costo dependen del tipo de procesamiento, tratamiento de la información y software utilizado para lograr altas precisiones (Ferhat et al. 2015), no obstante, es posible aplicar el misma metodología a las observaciones generadas con los equipos de bajo costo que las de los equipos geodésicos. En el estado del arte, los trabajos que han empleado equipos de bajo costo suelen estar orientados al uso y prueba a través de métodos como el Diferencial GPS (DGPS) o Cinemático en Tiempo Real (RKT), así mismo, la precisión de los equipos de bajo costo ha sido evaluada en aplicaciones como agricultura moderna (Keskin et al. 2017), ciencias forestales (Tomaštík et al. 2017), sistema de prevención sísmica (Saunders et al. 2016), monitoreo de laderas (Cina y Piras 2015), evaluación del posicionamiento obtenido en RTK bajo las normas ISO (Garrido-Carretero et al. 2019; Tsakiri et al. 2017), evaluación de líneas base geodésicas (ZamoraMaciel et al. 2020), evaluación de la técnica PPP en sistemas embebidos 
mediante software académico (Romero-Andrade et al. 2019), en costas para medir el nivel del mar (Knight et al. 2020), así como su rendimiento (Cina y Piras 2015; Guo et al. 2018).

En este sentido, se han llevado a cabo diversos estudios para probar la funcionalidad y rendimiento de los equipos de bajo costo en distintos ambientes. Dado lo anterior, el objetivo principal de este trabajo es probar la factibilidad de utilizar los equipos de bajo costo en trabajos topógrafosgeodésicos, por ello, el receptor de bajo costo es evaluado bajo el método relativo estático y de Posicionamiento Puntal Preciso (PPP). Para esto, se tomó como referencia las coordenadas alcanzadas con el receptor geodésico, siendo así contrastados en los mismos términos acorde con las normas técnicas para levantamientos geodésicos que señala el Instituto Nacional de Estadística y Geografía (INEGI).

\section{Marco teórico}

\section{Método de Posicionamiento Puntual Preciso y Relativo Estático}

El posicionamiento relativo estático es comúnmente usado para llevar a cabo el procesamiento de las mediciones en los trabajos topógrafogeodésicos, el cual consiste (para una línea base simple) en permanecer dos receptores (uno con coordenadas conocidas) estacionarios durante toda la medición. Este método está directamente relacionado con la longitud de la línea base, el tiempo de observación (la precisión es correlacionada con la longitud de la línea base y asciende a 1 por 0.1 ppm para líneas base de hasta unos $100 \mathrm{~km}$, e incluso mejor para líneas base más largas), el número satélites visibles y su configuración geométrica, así como el número de frecuencias del receptor (Hofmann-Wellenhof et al. 2008). De acuerdo con HofmannWellenhof et al. (2008); Vazquez et al. (2017) el método relativo estático para la combinación de la fase portadora resolviendo las dobles diferencias (DD) es dada por:

$$
\begin{gathered}
\Phi_{i j, 12}^{k l}=\rho_{i j}^{k l}+T_{i j}^{k l}+\alpha_{1} \lambda_{1} N_{1}+\alpha_{2} \lambda_{1} N_{2}+\alpha_{1} \varepsilon_{i j, 1}^{k l}+\alpha_{2} \varepsilon_{i j, 2}^{k l} \\
\alpha_{1}=\frac{f_{1}^{2}}{f_{1}^{2}-f_{2}^{2}}, \alpha_{2}=-\frac{f_{2}^{2}}{f_{1}^{2}-f_{2}^{2}}
\end{gathered}
$$

Dónde: i y j corresponden a los receptores; $\mathrm{k}$ y $l$ corresponden a los satélites; $\rho$ es la distancia geométrica entre el receptor y el satélite; 1 y 2 son las portadoras $L_{1}$ y $L_{2}$ involucradas en la combinación respectivamente; $\mathrm{T}$ es la DD para la refracción de la tropósfera; $\lambda_{1} \approx 19 \mathrm{~cm} \mathrm{y} \lambda_{2} \approx 24 \mathrm{~cm}$ son las longitudes de onda de las señales en la portadora $L_{1}$ y $L_{2}$ respectivamente; $N_{1}$ y $N_{2}$ son las ambigüedades enteras asociadas con las mediciones de fase en $L_{1}$ y $L_{2}$ respectivamente; $\varepsilon$ es el ruido aleatorio DD de las mediciones observado en las fases en $L_{1}$ y $L_{2}$ en $\mathrm{m}$. 
Por otro lado, el PPP es un método donde se utiliza un solo receptor, el cual usa observaciones de doble frecuencia de pseudorango y de fase portadora, además de información GNSS de los relojes de los satélites y productos orbitales. En este sentido, PPP puede proveer precisión en modo estático en el orden del centímetro o decímetro (Alkan et al. 2020). De la misma forma, de acuerdo con Alkan et al. (2015); Cai et al. (2010), las ecuaciones (3 y 4) de observación para el modelo matemático PPP considerando las constelaciones GLONASS y GPS doble frecuencia $\left(L_{1}\right.$ y $\left.L_{2}\right)$ son dadas por:

$$
\begin{aligned}
& P_{i}^{g r}=\rho_{g r}+c d t^{g r}-c d T^{g r}+d_{o r b}^{g r}+d_{\text {trop }}^{g r}+d_{i o n / P_{i}}^{g r}+d_{m u l t / P_{i}}^{g r}+\varepsilon_{P_{i}}^{g r} \\
& \Phi_{i}^{g r}=\rho_{g r}+c d t^{g r}-c d T^{g r}+d_{o r b}^{g r}+d_{\text {trop }}^{g r}-d_{\text {ion } / \Phi_{i}}^{g r}+\lambda_{i}^{g r} N_{i}^{g r}+d_{m u l t / \Phi i}^{g r}+ \\
& \varepsilon_{\Phi i}^{g r}
\end{aligned}
$$

Donde: $\mathrm{g}$ y r corresponde a los satélites GPS y GLONASS respectivamente; $P_{i}$ es el pseudorango en $L_{i}$ en m; $\Phi_{i}$ es la fase portadora en $L_{i}$ en m; $\rho$ es verdadero rango geométrico en $\mathrm{m} ; c$ es la velocidad de la luz en m por s; dt y $\mathrm{dT}$ es el error del reloj en el recetor y satélite en m respectivamente en m; $d_{\text {orb }}$ es el error del satélite en m; $d_{\text {trop }}$ es el retardo troposférico en $\mathrm{m} ; d_{\text {ion }}$ es el retardo ionosférico en m; $\lambda_{i}$ es la longitud de onda en $L_{i}$ en m por ciclo; $N_{i}$ es la ambigüedad de la fase entera en $L_{i}$ en m por ciclo; $d_{m u l t / \Phi i}$ es el efecto de multitrayectoria en la fase portadora $L_{i}$ en $\mathrm{m} ; d_{m u l t / p_{i}}$ es el efecto de multitrayectoria de pseudorango en la $L_{i}$ en $\mathrm{m} ; \varepsilon$ es el ruido en las mediciones en $\mathrm{m}$.

\section{Circulo de Error Probable}

Como parte de la evaluación del posicionamiento obtenido a través del método PPP, se llevó a cabo el análisis de la precisión a través de la "Norma técnica de estándares de exactitud posicional" (INEGI 2010) implementada por el Instituto Nacional de Estadística y Geografía (INEGI) en México, la cual permite evaluar la exactitud posicional horizontal (Circulo del Error Probable, CEP) (Ecuación 5) y vertical (Exactitud de Posicionamiento Vertical, EPV) (Ecuación 6) obtenida en un intervalo de confianza del 95\%:

$$
\begin{gathered}
C E P=1.2238\left(\sigma_{\Phi}+\sigma_{\lambda}\right) \\
E P V=1.9600\left(\sigma_{G N S S}^{2}+\sigma_{N}^{2}\right)^{1 / 2}
\end{gathered}
$$

Donde: $\sigma_{\Phi}$ y $\sigma_{\lambda}$ es la desviación estándar de la latitud y longitud respectivamente, en metros; $\sigma_{G N S S}$ es la desviación estándar del punto para la altura; $\sigma_{N}$ es la desviación estándar del modelo de alturas geoidales. Según la norma, dependiendo de los requerimientos de exactitud de un levantamiento en particular se podrá catalogar un punto en un orden de exactitud. En este sentido, se establecen dos órdenes para alta precisión para el cálculo del CEP: orden de 5 centímetros, el cual deberá aplicarse a los trabajos encaminados a establecer un sistema geodésico de referencia nacional; orden de 1 decímetro, 
se destinará a levantamientos geodésicos de densificación del sistema geodésico nacional básico. Para el caso del EPV, se considerará el criterio del CEP, ya que no se realizó una nivelación GNSS (circuitos), sin embargo, es importante ver el comportamiento de la componente vertical al introducir el modelo planteado por INEGI.

\section{Transformación de coordenadas a la época oficial en México ITRF08 época 2010.0}

De acuerdo a las normas vigentes en México en cuestión de procesamiento de datos GNSS, es necesario considerar las deformaciones del Marco Geodésico en el tiempo, esto considerando que el país de México es altamente sísmico (INEGI 2016). Por ello, se ha establecido que toda medición con equipo GNSS deberá ser referida al ITRF08 época 2010.0, esto para minimizar errores debido a la deformación del marco de referencia del ITRF. Actualmente, las coordenadas de las estaciones de las redes geodésicas nacionales o regionales se publican con respecto a un marco de referencia determinado, siendo válida únicamente para esa misma época. En este sentido, la norma nacional establece que toda medición deberá ser referida al ITRF08 época 2010.0, y, a su vez, aplicar el nuevo esquema de procesamiento y ajuste de datos. La metodología consta de tres etapas:

- Antes del procesamiento y ajuste: obtener las coordenadas en las estaciones de referencia en la época de medición de los datos a procesar.

- Procesamiento y ajuste de los datos: utilizando las coordenadas de las estaciones de referencia en la época de medición de los datos.

- Después del procesamiento y ajuste: llevar las coordenadas resultantes del ajuste, que están en la época de medición a la época 2010.0.

Con base en lo anterior, la Ecuación 7 será utilizada para llevar la estación de referencia a la época de las observaciones GNSS considerando sus velocidades; la Ecuación 8, será para transformar a la época oficial considerando el modelo de placas tectónicas ITRF08 PPM (Altamimi et al. 2012), ya que este modelo describe de manera adecuada las deformaciones de la corteza en gran parte del territorio mexicano; la Ecuación 9, será usada para calcular la diferencia entre la época de medición de los datos a procesar (época B) y la época del marco oficial (época A)

$$
\begin{gathered}
{\left[\begin{array}{l}
X_{B} \\
Y_{B} \\
Z_{B}
\end{array}\right]=\left[\begin{array}{l}
X_{A} \\
Y_{A} \\
Z_{A}
\end{array}\right]+\delta t\left[\begin{array}{l}
V_{X} \\
V_{Y} \\
V_{Z}
\end{array}\right]+\left[\begin{array}{l}
E_{X} \\
E_{Y} \\
E_{Z}
\end{array}\right]} \\
{\left[\begin{array}{l}
X_{A} \\
Y_{A} \\
Z_{A}
\end{array}\right]=\left[\begin{array}{l}
X_{B} \\
Y_{B} \\
Z_{B}
\end{array}\right]-\delta t\left[\begin{array}{ccc}
0 & -\omega_{Z} & \omega_{Y} \\
\omega_{Z} & 0 & -\omega_{X} \\
-\omega_{Y} & \omega_{X} & 0
\end{array}\right]\left[\begin{array}{l}
X_{B} \\
Y_{B} \\
Z_{B}
\end{array}\right]-\left[\begin{array}{l}
E_{X} \\
E_{Y} \\
E_{Z}
\end{array}\right]} \\
\delta t=a \tilde{n} o+(\text { doy } / 365)
\end{gathered}
$$


Donde: $\left(X_{A}, Y_{A}, Z_{A}\right)$ son las coordenadas de la estación en la época de origen; $\left(X_{B}, Y_{B}, Z_{B}\right)$ son las coordenadas en la época de destino; $\delta t$ tiempo transcurrido entre la época A y B; doy, número de días del año transcurridos; $\left(E_{X}, E_{Y}, E_{Z}\right)$ son los desplazamientos episódicos; $\left(V_{X}, V_{Y}, V_{Z}\right)$ son las velocidades para la estación de referencia; $\omega_{X}, \omega_{Y}, \omega_{Z}$ son los valores de rotación de Euler en correspondencia al vector de rotación del modelo de placas ITRF08 PPM (Altamimi et al. 2012).

\section{Análisis de calidad de las observaciones}

Como parte importante de cualquier trabajo topógrafo-geodésico, el análisis de las observaciones GNSS generadas durante el posicionamiento es una de las principales consideraciones a tomar, principalmente en términos de: integridad, efecto multitrayectoria, relación señal ruido y pérdida de saltos de ciclo. La calidad de la estación no solo depende de circunstancias del receptor o de la antena, sino también de la estabilidad de la localización (Herrada et al. 2010; Souto 2014). En este sentido, el control puede ser llevado a cabo implementando el software TEQC (Estey et al. 1999) que son encontrados en su archivo de calidad:

- Efecto multitrayectoria: acorde con Vázquez et al. (2013); Souto (2014); Wang et al. (2017); uno de los principales efectos que degrada la señal GNSS es el efecto de multitrayectoria (MP), el cual es causado por la señal reflejada de los objetos que rodean la antena GNSS. Igualmente, este efecto se calcula mediante una combinación lineal de fase y peudorango en $L_{1}$ y $L_{2}$ en m; esto teniendo como valores comunes de entre 20 y $30 \mathrm{~cm}$ en $L_{1}$ y $L_{2}$ respectivamente.

- Integridad: teóricamente es posible calcular el porcentaje de las observaciones reales que la estación ha realizado (integridad), esto, considerando las observaciones completadas respecto a las observaciones posibles (Souto 2014).

- Saltos de ciclo: este análisis es considerado como fundamental, ya que representa la capacidad del receptor para permanecer en enlace con el satélite. Esto es calculado a través de la fase observada: cuando se realiza el seguimiento de la fase, esto genera un número entero de ciclo que está asociado a cada satélite (ambigüedad inicial), si la señal se pierde o se interrumpe genera una nueva ambigüedad inicial en la señal medida (Cycle slip). Este indicador es calculado mediante los valores proporcionados por TEQC y la relación $C S R=\frac{1000}{o / \text { slips }}$ (Xiao et al. 2020); donde "o/slips" es el número de observaciones entre saltos de ciclo.

- Relación señal ruido: es un parámetro que influye en el rendimiento y el estado operativo del sistema (receptor, antena, señal), sin embargo las variaciones son principalmente por la potencia de la señal satelital, la 
ganancia de la antena, estado del receptor y efecto multitrayectoria (Xiao et al. 2020); siendo este último inversamente proporcional a la relación señal ruido (Kamatham 2018); generalmente, en el exterior el valor normal oscila entre 35 a $55 \mathrm{dBHz}$.

\section{Materiales y métodos}

El proceso de experimentación se llevó a cabo a través de las etapas expuestas en la Figura 1.

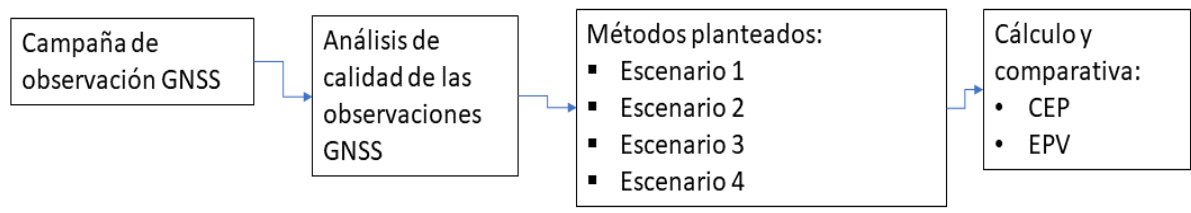

Figura 1. Metodología propuesta para el análisis de las observaciones GNSS

Como fase inicial, se planteó un lugar con horizonte despejado, evitando obstrucciones en la antena, para ello, los equipos se colocaron sobre un vértice geodésico de centrado forzoso en la comunidad de Sanalona, en Sinaloa, México (Figura 2 y $3 b$ ).

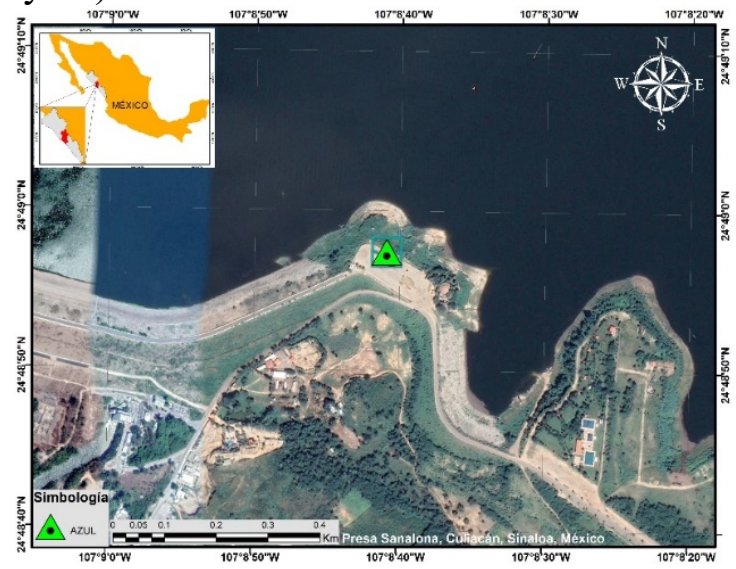

Figura 2. Localización del vértice geodésico utilizado en Sinaloa, México.

Consecuentemente, se realizó una campaña de observación con el equipo de bajo costo (16 de junio de 2020) y el receptor geodésico (20 de diciembre de 2019), esto, con la finalidad de tener soluciones independientes, y a su vez, no dependientes de los mismos parámetros orbitales (ya que al procesar en cualquier época considerando los mismos modelos, teóricamente se obtendría resultados similares). Una vez obtenidas las observaciones GNSS, se llevó a cabo el análisis de calidad. Con base en lo anterior y con el objetivo de comparar el desempeño de la precisión que es posible obtener a través del método relativo estático y PPP, se platearon los siguientes escenarios: 
- Escenario 1: Procesado en modo relativo estático con la estación CULC y un receptor de bajo costo, considerando una distancia aproximada de $33 \mathrm{~km}$.

- Escenario 2: Procesado en modo relativo estático con la estación CULC y un receptor geodésico, considerando una distancia aproximada de $33 \mathrm{~km}$.

- Escenario 3: Procesado en modo PPP estático con un receptor geodésico.

- Escenario 4: Procesado en modo PPP estático con un receptor de bajo costo.

De acuerdo con lo anteriormente descrito, se realizó una comparativa entre las precisiones obtenidas de cada escenario a través del CEP, EVP y de las coordenadas geodésicas transformadas a la época oficial en México ITRF08 época 2010.0, esto debido a las diferentes fechas en la recolección de los datos GNSS.

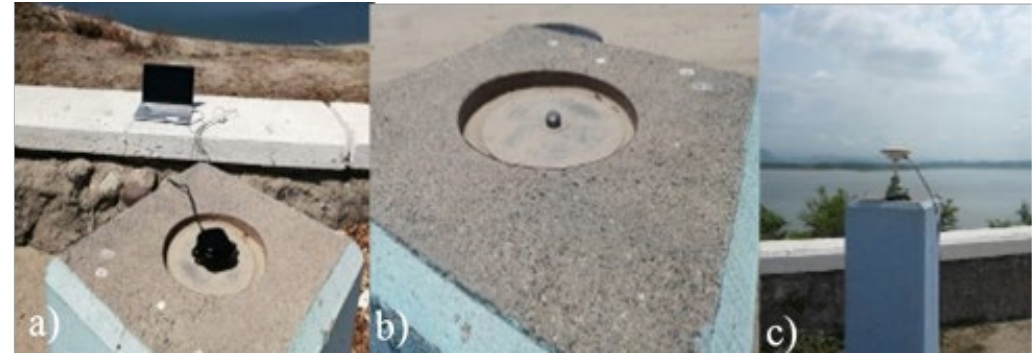

Figura 3. Equipos GNSS en vértice geodésico de centrado forzoso. Figura a) Antena y receptor de bajo costo. Figura b) Vértice geodésico de centrado forzoso. Figura c) Receptor geodésico.

\section{Receptor GNSS de bajo costo}

Se empleó un receptor de bajo costo (low-cost) de la marca U-blox (Tabla 1 y Figura $4 \mathrm{~b}$ ) de alta sensibilidad (acorde con el fabricante), mismo que fue utilizado con una antena ANN-MB multi band activa (Tabla 1 y Figura 4a). El receptor de bajo costo fue operado por medio del software RTKLIB (Takasu 2013) en Windows para llevar a cabo las observaciones. Una vez generadas, fueron convertidas del formato RAW a U-blox, para posteriormente transformarlas a RINEX 2.11 (Gurtner 1994), lo cual se realizó con el software RTKLIB.

Tabla 1. Características del recepto de bajo costo y antena

\begin{tabular}{|c|c|c|c|}
\hline \multicolumn{3}{|l|}{ Receptor: ZED-F9P } & \multirow{2}{*}{$\begin{array}{l}\text { Antena: } \\
\text { ANN-MB }\end{array}$} \\
\hline Tipo de receptor & $\begin{array}{ll}\text { Tiempo } & \text { de } \\
\text { convergencia }\end{array}$ & Sensibilidad & \\
\hline $\begin{array}{l}184 \text { canales, U-blox } \\
\text { F9 } \\
\text { GPS L1C/A L2C, } \\
\text { GLO L1OF L2OF, } \\
\text { GAL E1B/C E5b, } \\
\text { BDS B1I B2I, }\end{array}$ & $\begin{array}{l}\text { RTK }<10 \mathrm{~s} \\
\text { Adquisición } \\
\text { inicio frío }(24 \mathrm{~s}) \\
\text { Reacción }(2 \mathrm{~s})\end{array}$ & $\begin{array}{lr}\text { Seguimiento } & \mathrm{y} \\
\text { navegación } & -167 \\
\mathrm{dBm} & \\
\text { Inicio frío }-148 \mathrm{dBm} \\
\text { Inicio caliente } & -157 \\
\mathrm{dBm} & \end{array}$ & $\begin{array}{l}\text { Multibanda } \\
\text { L2/E5b). } \\
\text { Sistemas } \\
\text { GLONASS, } \\
\begin{array}{l}\text { GALILEO } \\
\text { BeiDou }\end{array} \\
\end{array}$ \\
\hline
\end{tabular}




\begin{tabular}{|l|l|l|l|}
\hline QZSS L1C/A L2C & Reacción -160 dBm & \\
\hline
\end{tabular}

a)

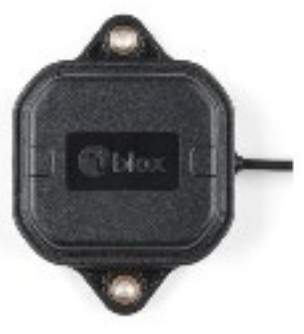

b)

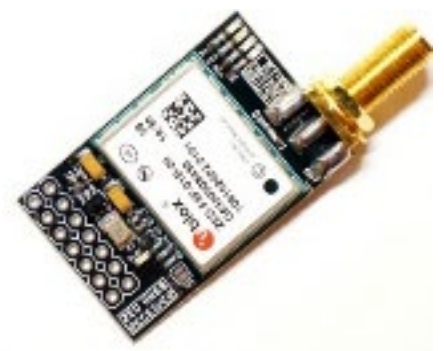

Figura 4. Equipo de bajo costo U-blox. Figura a) antena ANN-MB Multi-Band.

Figura b) Receptor ZED-F9P RTK.

\section{Datos GNSS y esquema de procesamiento}

Como parte de la experimentación se presentan las características de las observaciones (Tabla 2) considerando ambas técnicas (relativo estático y PPP). Para la técnica relativo estático se empleó la estación de referencia CULC que es operada por INEGI, la cual está a un intervalo de muestreo de $15 \mathrm{~s}$, con una distancia aproximada de $33 \mathrm{~km}$ al vértice de nombre AZUL utilizado para la experimentación. Por otro lado, los datos recabados con el receptor de bajo costo, fueron configurados a 2 segundos con un ángulo de elevación de $15^{\circ}$ (libre de obstrucciones para la antena), con un mayor tiempo de observación, el cual, acorde con Choy et al. (2017) se necesita medir $>60$ min para lograr una precisión de $5 \mathrm{~cm}$ (horizontal) en la técnica PPP; a su vez, el receptor geodésico fue configurado a un intervalo de muestreo de $1 \mathrm{~s}$, con motivo de reducir el tiempo de observación y comprobar la convergencia del método PPP. Para el caso del método relativo estático, las observaciones en ambos casos (azull y azul2) se llevaron a un muestreo $15 \mathrm{~s}$ conforme a la estación de referencia continua CULC mediante el software TEQC (Translate/Edit/Quality Check) (Estey et al. 1999).

Tabla 2. Características de las observaciones GNSS

\begin{tabular}{|c|c|c|c|}
\hline Parámetro & $\begin{array}{c}\text { Equipo de bajo } \\
\text { costo }\end{array}$ & $\begin{array}{c}\text { Receptor } \\
\text { geodésico }\end{array}$ & $\begin{array}{c}\text { Estación de } \\
\text { referencia }\end{array}$ \\
\hline Nombre & Azul1 & Azul2 & CULC \\
\hline $\begin{array}{c}\text { Intervalo de } \\
\text { muestreo }\end{array}$ & $2 \mathrm{~s}$ & $1 \mathrm{~s}$ & $15 \mathrm{~s}$ \\
\hline $\begin{array}{c}\text { Ángulo de } \\
\text { elevación }\end{array}$ & $15^{\circ}$ & $15^{\circ}$ & $15^{\circ}$ \\
\hline Constelación & $\begin{array}{c}\text { GPS+GLONASS } \\
+\end{array}$ & $\begin{array}{c}\text { GPS+GLONASS+ } \\
\text { GALILEO } \\
\text {-OU }\end{array}$ & $\begin{array}{c}\text { GPS+GLONASS } \\
+ \\
\text { GALILEO }\end{array}$ \\
\hline $\begin{array}{c}\text { Tiempo de } \\
\text { observación }\end{array}$ & $2.044 \mathrm{~h}$ & $1.268 \mathrm{~h}$ & $24 \mathrm{~h}$ \\
\hline
\end{tabular}




\begin{tabular}{|c|c|c|c|}
\hline $\begin{array}{c}\text { Fecha de } \\
\text { observación }\end{array}$ & $\begin{array}{c}16 \text { de junio de } \\
2020\end{array}$ & $\begin{array}{c}20 \text { de diciembre de } \\
2019\end{array}$ & $\begin{array}{c}\text { Mismas fechas } \\
\text { para el método } \\
\text { relativo estático }\end{array}$ \\
\hline
\end{tabular}

El procesamiento de las observaciones GNSS para el método PPP se realizó a través del software RTKLIB en su versión 2.4.2 considerando los parámetros expuestos en la Tabla 3. Para llevar a cabo el procesado con PPP las observaciones de fase y código fueron usadas considerando un ángulo de elevación de $15^{\circ}$ (los valores típicos para la máscara de elevación son entre 10 ${ }^{\circ}$ y $15^{\circ}$ ) (Leick et al. 2015) a 2 s y 1 s para la estación azull y azul2 respectivamente. Para el efecto ionosférico se aplicó el modelo libre de ionosfera mediante una combinación lineal de $\mathrm{L}_{1}$ y $\mathrm{L}_{2}$ implementado en RTKLIB. Asimismo, se empleó el modelo de Saastamoinen para la Troposfera (Saastamoinen 1973). Adicionalmente, se usó el IGS08.atx para la corrección del centro de fase de la antena fue utilizada en conjunto con las efemérides finales del IGS ("sp3") y archivos de efemérides transmitidas ("n"). Se aplicó la corrección debido al avance de la fase y el retraso por la rotación relativa entre el receptor y la antena del satélite (phase windup correction), así como la corrección de las mareas terrestres considerando la convención del IERS 2010 (Luzum y Petit 2010). Finalmente para la resolución de la ambigüedad, se consideró el parámetro continuo, esto acorde con Takasu (2013); las ambigüedades de la fase portadora flotantes pueden resolverse en valores enteros para mejorar la precisión y el tiempo de convergencia.

Tabla 3. Parámetros de procesamiento aplicados en el software RTKLIB

\begin{tabular}{|l|l|}
\hline Observaciones & Fase y código \\
\hline Frecuencia & Doble \\
\hline Modo & Estático \\
\hline Ángulo de elevación & $15^{\circ}$ \\
\hline Órbita de satélites & IGS finales (“.sp3"), y archivos transmitidos (“.n”) \\
\hline Modelo ionosférico & $\mathrm{L}_{1}$ y L2, libre de ionosfera implementado en RTKLIB. \\
\hline Modelo troposférico & Saastamoinen \\
\hline Marco de referencia & $\begin{array}{l}\text { ITRF14 a la época de las observaciones y transformado a } \\
\text { la referencia oficial ITRF08 2010.0 }\end{array}$ \\
\hline $\begin{array}{l}\text { Resolución de } \\
\text { ambigüedades }\end{array}$ & Continuas \\
\hline $\begin{array}{l}\text { Corrección de las mareas } \\
\text { terrestres }\end{array}$ & Sólida \\
\hline $\begin{array}{l}\text { Corrección de la fase } \\
\text { "windup" }\end{array}$ & Aplicada \\
\hline $\begin{array}{l}\text { Corrección del centro de } \\
\text { fase }\end{array}$ & IGS08.atx \\
\hline
\end{tabular}

Por otro lado, para el procesado de la información mediante el software comercial, los parámetros considerados se encuentran en la Tabla 4. 
Tabla 4. Parámetros de procesamiento aplicados en el software comercial

\begin{tabular}{|c|c|}
\hline Observaciones & Fase y código \\
\hline Frecuencia & Doble \\
\hline Modo & Relativo estático \\
\hline Ángulo de elevación & $15^{\circ}$ \\
\hline Tipo de producto & IGS finales “.sp3” y archivos de efemérides transmitidas “.n” \\
\hline Estación de referencia & CULC \\
\hline
\end{tabular}

Para el cálculo de las alturas, se implementó el geoide gravimétrico mexicano en su versión 2010 (GGM10), con una resolución de 2.5 min de arco (aproximadamente $4.5 \mathrm{~km}$ ), que representa las alturas geoidales medidas en dirección vertical, esto acorde con la normatividad de INEGI con la transformación al ITRF08 época 2010.0, lo cual fue realizado mediante el software SIAG10 proporcionado por INEGI (disponible en https://www.inegi.org.mx/temas/geoide/default.html\#Herramientas).

\section{Resultados}

\section{Análisis de calidad de las observaciones GNSS}

La Tabla 5 presenta los cuatro escenarios evaluados; los primeros dos, son las estadísticas de la estación de referencia CULC utilizada para el método relativo estático. De acuerdo con el International GNSS Service (2015), solamente los valores de integridad y saltos de ciclo en ambos escenarios están dentro de lo recomendado, siendo la integridad mayor al 95\%, a su vez, los saltos de ciclo son menores a 1 por cada mil observaciones. No obstante, los valores de multitrayectoria están por encima de lo recomendado, siendo mayores a $0.30 \mathrm{~m}$ para ambos escenarios. Respecto a la relación señal ruido (SNR), para ambas bandas se presenta con señales fuertes, estando por encima de los $36 \mathrm{~dB}-\mathrm{Hz}$, lo que refleja una correcta recepción de las señales (Xiao et al. 2020). Tanto las constelaciones, muestreo y tiempo de observación se mantienen constantes para ambos escenarios, caso contrario para el total de satélites, disminuyendo en dos satélites.

El tercer escenario denominado Azul2 se apega en gran medida a los estándares internacionales a excepción del porcentaje de integridad, al ser menor del 95\%, no obstante, presenta valores bajos de efecto multitrayectoria y recepción de señales fuertes, así como pocos saltos de ciclo. El cuarto escenario corresponde a Azull presentando señales fuertes en ambas bandas, no obstante, supera el medio metro de efecto multitrayectoria, y un porcentaje de integridad del $64 \%$ así como una cantidad considerable de saltos de ciclo, sin embargo, es el único receptor que observó BEIDOU a diferencia de los otros receptores solo con GPS, GALILEO y GLONASS.

Tabla 5. Resultados del análisis de calidad para las observaciones generadas.

\begin{tabular}{|l|l|l|l|l|l|l|l|l|l|}
\hline $\begin{array}{l}\text { Estació } \\
\text { n }\end{array}$ & $\begin{array}{l}\text { Tiempo } \\
\text { de }\end{array}$ & $\begin{array}{l}\text { Interval } \\
\text { o de }\end{array}$ & $\begin{array}{l}\text { Integri } \\
\text { dad } \\
(\%)\end{array}$ & $\begin{array}{l}\text { MP } \\
\mathbf{1} \\
(\mathrm{m})\end{array}$ & $\begin{array}{l}\text { MP } \\
\mathbf{2} \\
(\mathrm{m})\end{array}$ & $\begin{array}{l}\text { SNR } \\
\mathbf{1}\end{array}$ & $\begin{array}{l}\text { SNR } \\
\mathbf{2}\end{array}$ & CRS & $\begin{array}{l}\text { Númer } \\
\text { ore } \\
\text { satélite }\end{array}$ \\
\hline
\end{tabular}




\begin{tabular}{|l|l|l|l|l|l|l|l|l|l|}
\hline & $\begin{array}{l}\text { observa } \\
\text { ción (h) }\end{array}$ & $\begin{array}{l}\text { muestre } \\
\text { o(s) }\end{array}$ & & & & $\begin{array}{l}\text { (dB- } \\
\text { Hz) }\end{array}$ & $\begin{array}{l}\text { (dB- } \\
\text { Hz) }\end{array}$ & & \\
\hline CULC1 & 24 & 15 & 96 & $\begin{array}{l}0.3 \\
5\end{array}$ & $\begin{array}{l}0.3 \\
9\end{array}$ & 46.27 & 42.48 & $\begin{array}{l}0.35 \\
1\end{array}$ & 76 \\
\hline CULC2 & 24 & 15 & 100 & $\begin{array}{l}0.3 \\
8\end{array}$ & $\begin{array}{l}0.4 \\
1\end{array}$ & 46.65 & 42.25 & $\begin{array}{l}0.55 \\
1\end{array}$ & 74 \\
\hline Azul1 & 2.044 & 2 & 64 & $\begin{array}{l}0.5 \\
8\end{array}$ & $\begin{array}{l}0.6 \\
2\end{array}$ & 39.68 & 37.4 & 4 & 46 \\
\hline Azul2 & 1.268 & 1 & 80 & $\begin{array}{l}0.0 \\
9\end{array}$ & $\begin{array}{l}0.1 \\
1\end{array}$ & 41.93 & 41.38 & $\begin{array}{l}0.06 \\
7\end{array}$ & 19 \\
\hline
\end{tabular}

En este sentido, la Figura 5 representa los valores del efecto multitrayectoria para las estaciones, donde las CULC y Azull superan los valores recomendados por el IGS (línea roja, con un valor de $0.30 \mathrm{~m}$ ), sin embargo, Azul2 presenta una respuesta baja en los valores del efecto multitrayectoria.

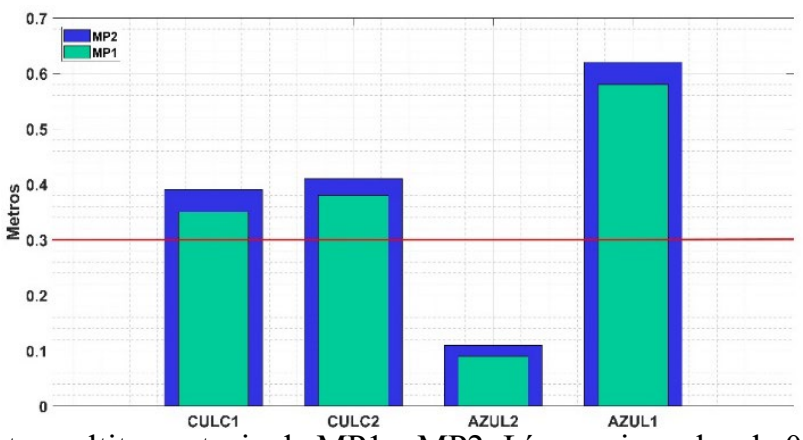

Figura 5. Efecto multitrayectoria de MP1 y MP2. Línea roja: valor de $0.30 \mathrm{~m}$ máximo para el efecto multitrayectoria (International GNSS Service 2015).

La Figura 6, muestra el resultado de la relación señal-ruido, los cuales se encuentran en un rango de 37.4-46.6 dBHz teniendo una buena calidad según Xiao et al. (2020). Según Kamatham (2018) presenta que la relación señal ruido es inversamente proporcional al efecto de multitrayectoria; cuando la señal recibida es débil, el efecto multitrayectoria es alto, esto es visto en el receptor geodésico (Azu12); no obstante, los resultados para el receptor de bajo costo presentan una relación señal ruido fuerte superando los $36 \mathrm{dBHz}$, sin embargo, el valor del efecto multitrayectoria es alto. Los valores presentados en las Figuras 5-6, pueden estar relacionados con el tipo de antena utilizado para la experimentación, ya que no cuenta con equipamiento para reducir el efecto multitrayectoria. 


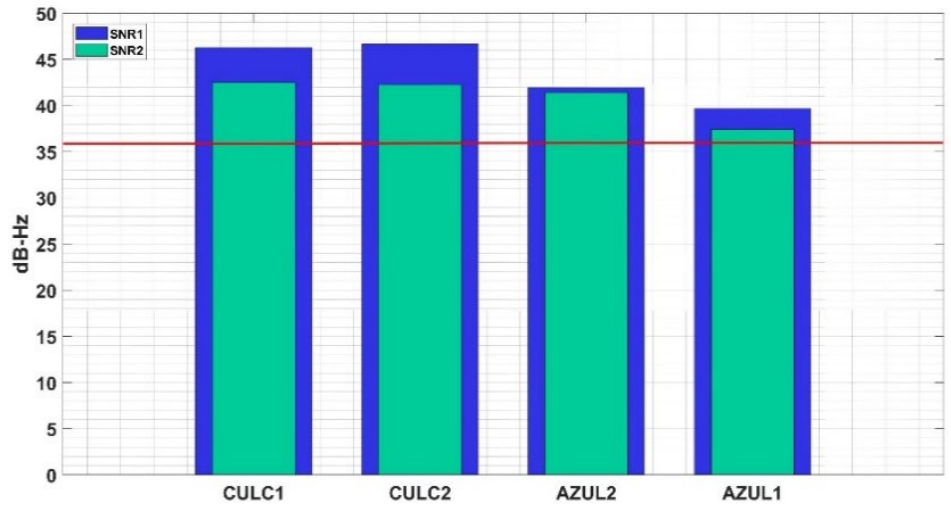

Figura 6. Relación señal ruido (SNR). Línea roja: 36 dB-Hz según Xiao et al. (2020)

Con respecto a los saltos de ciclo, se espera que por cada 1000 observaciones se pierda una, para las estaciones de CULC, Azul2 no superan el valor del estándar, sin embargo, para la estación Azull presenta un valor elevado de saltos de ciclo (Figura 7). Esto mismo impacta en la integridad de las observaciones (Figura 8), la cual muestra un desempeño bajo superando el $50 \%$ de las observaciones durante toda la campaña.

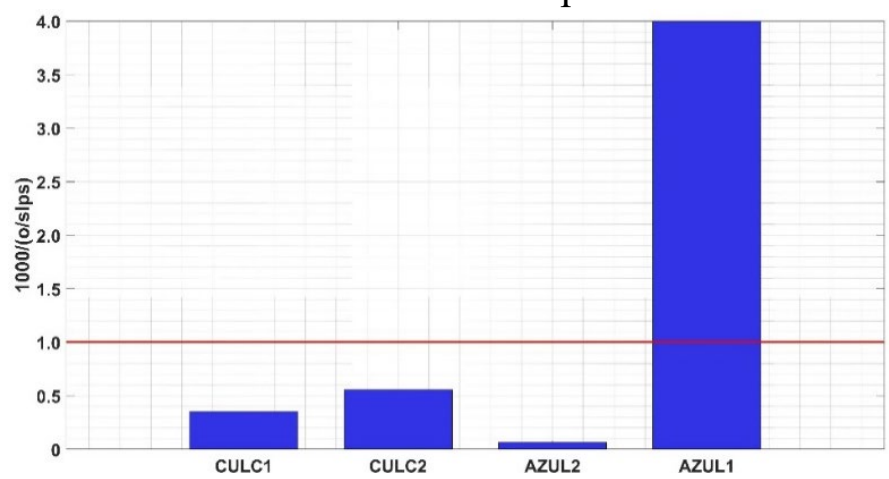

Figura 7. Saltos de ciclo por cada 1000 observaciones. Línea roja: $1000 /($ o/slips $)<1$ CSR

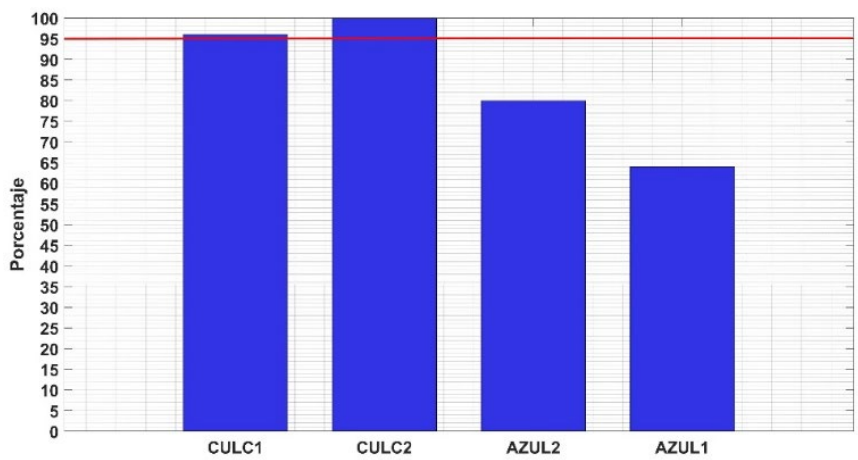

Figura 8. Porcentaje de integridad. Línea roja: $95 \%$ integridad. 


\section{Evaluación del Circulo del Error Probable (CEP)}

En la Tabla 6 y Figura 9, se presenta el resultado de evaluar el CEP y EPV para la técnica PPP a un intervalo de confianza de 95\%, en las cuales, se encuentra que, para el caso del receptor de bajo costo, es posible aplicarlo para un establecimiento de un sistema geodésico, esto debido a que los valores son $<5 \mathrm{~cm}$ para el CEP. Por otro lado, con base en el cálculo del EPV, se muestra que en ambos casos siguen siendo valores de baja calidad, ya que supera considerablemente el valor de $1 \mathrm{dm}$. Esto puede ser afectado dado que, el modelo implementado GGM10 cuenta con una desviación estándar de $20 \mathrm{~cm}$, lo cual está relacionado con el cálculo del EPV, así mismo, de considerar la altura elipsoidal, la altura obtenida puede ser utilizable para el caso de los receptores de bajo costo a través de la técnica PPP.

Tabla 6. Cálculo del CEP y EPV de Posicionamiento Puntual Preciso conforme a la norma técnica expuesta por INEGI.

\begin{tabular}{|c|c|c|c|c|c|}
\hline Estación & $\boldsymbol{\sigma}_{\boldsymbol{\Phi}}$ & $\boldsymbol{\sigma}_{\boldsymbol{\lambda}}$ & $\boldsymbol{\sigma}_{\boldsymbol{h}}$ & $\boldsymbol{C E P}_{\mathbf{9 5}}$ & $\boldsymbol{E} \boldsymbol{P} \boldsymbol{V}_{\mathbf{9 5}}$ \\
\hline Azul1 & 0.0159 & 0.0183 & 0.0134 & 0.04185 & 0.393 \\
\hline Azul2 & 0.005 & 0.008 & 0.005 & 0.01652 & 0.392 \\
\hline
\end{tabular}

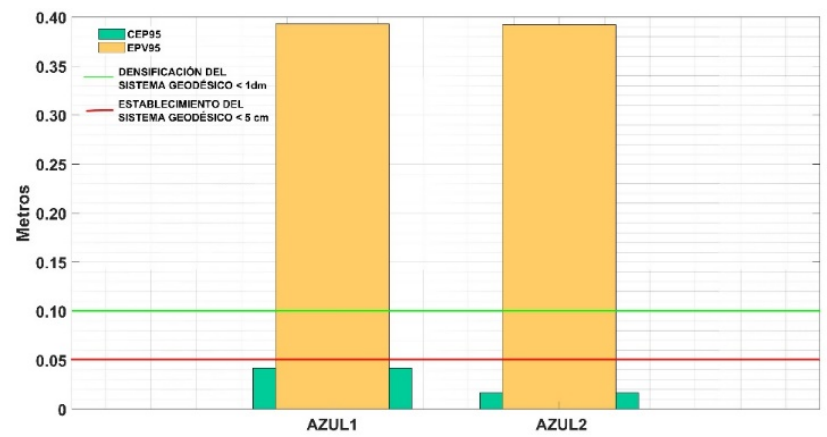

Figura 9. Diferencias del Circulo del Error Probable y Exactitud de Posicionamiento Vertical de PPP conforme a la norma técnica expuesta por INEGI, con relación a la Tabla 7.

Por otro lado, en la Tabla 7 y Figura 10, se presentan los resultados obtenidos para CEP y EPV para el método relativo estático. Según los valores calculados, en ambos casos (receptor bajo costo y geodésico), pueden ser utilizados para trabajos geodésicos de alta precisión. Asimismo, y con base a los valores calculados para el equipo de bajo costo, se encuentra un mejor desempeño del equipo de bajo costo para la técnica relativo estático, ya que, existe una diferencia absoluta de 0.0025 entre los valores del CEP obtenidos para el receptor de bajo costo y el receptor geodésico (Tabla 8); considerando el cálculo del EPV, no es recomendable utilizar en ambos casos la altura, no obstante, esto será en función de los requisitos del proyecto. Para el caso de 
no considerar el modelo GGM10, ambos casos son recomendables para establecer una base geodésica.

De acuerdo a las diferencias presentadas entre los valores del $\mathrm{CEP}_{95}$ para azul1 y azul2, y, debido al mejor desempeño del receptor de bajo costo que muestran los resultados, esto es en consecuencia de que el receptor de bajo costo (azul1) tiene un tiempo de observación mayor $(0.776 \mathrm{~h})$, derivado de la finalidad de probar la convergencia para el método PPP; así mismo, al no contar con parámetros de calibración de antena, fue necesario realizar un mayor tiempo de observación, esto acorde con Gezgin et al. (2016) ayuda a mejorar la precisión, sin embargo, en algunos casos puede estar sujeto al valor de la dilución de la precisión. En este mismo sentido, el receptor de bajo costo está configurado para recibir información de más constelaciones (BEIDOU) a diferencia de la estación de referencia (CULC) y del receptor geodésico (azul2).

Tabla 7. Cálculo del CEP y EPV de relativo estático conforme a la norma técnica expuesta por INEGI.

\begin{tabular}{|l|l|l|l|l|l|}
\hline Estación & $\boldsymbol{\sigma}_{\boldsymbol{\phi}}$ & \multicolumn{1}{|c|}{$\boldsymbol{\sigma}_{\boldsymbol{\lambda}}$} & $\boldsymbol{\sigma}_{\boldsymbol{h}}$ & $\boldsymbol{C E}_{\mathbf{9 5}}$ & $\boldsymbol{E} \boldsymbol{P} \boldsymbol{V}_{\mathbf{9 5}}$ \\
\hline Azul1 & 0.007 & 0.007 & 0.018 & 0.0171332 & 0.394 \\
\hline Azul2 & 0.008 & 0.007 & 0.016 & 0.0195808 & 0.393 \\
\hline
\end{tabular}

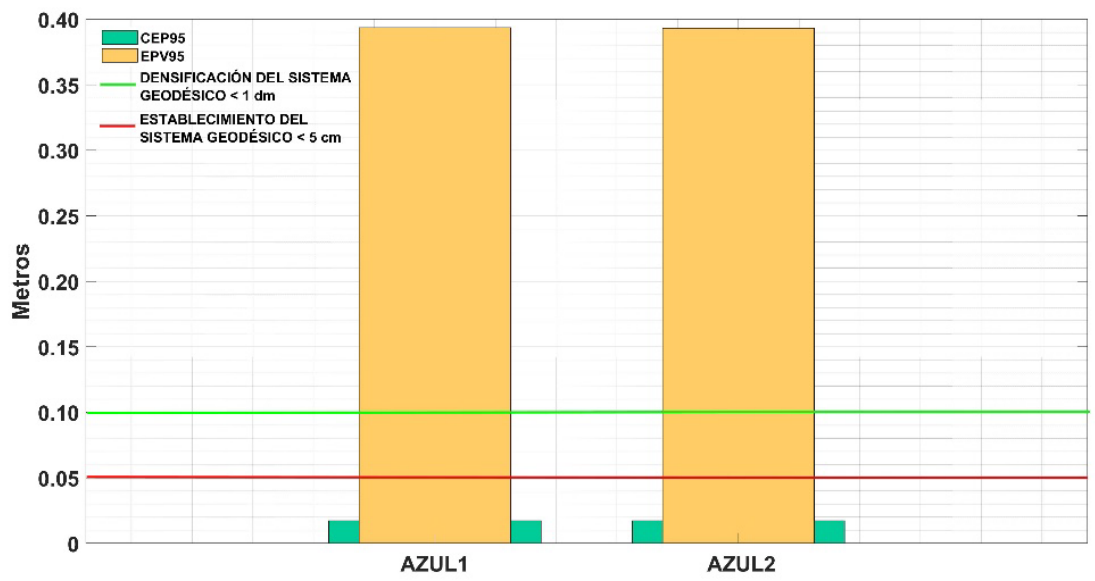

Figura 10. Diferencias del Circulo del Error Probable y Exactitud de Posicionamiento Vertical de relativo estático conforme a la norma técnica expuesta por INEGI, con relación a la Tabla 7 .

En la Tabla 8, se presentan las diferencias absolutas del cálculo del CEP y EPV entre las obtenidas mediante el método relativo estático y los dos receptores; así mismo, las diferencias absolutas del CEP y EPV entre los métodos relativo estático y PPP. 
Tabla 8. Diferencia absoluta del CEP y EPV para el Posicionamiento Puntal Preciso y el Relativo Estático.

\begin{tabular}{|c|c|c|c|c|c|c|}
\hline \multirow{2}{*}{ Estación } & \multicolumn{2}{|c|}{$\begin{array}{c}\text { Relativo } \\
\text { Estático }\end{array}$} & \multicolumn{2}{c|}{$\begin{array}{c}\text { Posicionamiento } \\
\text { Puntual Preciso }\end{array}$} & \multicolumn{2}{c|}{$\begin{array}{c}\text { Diferencia } \\
\text { absoluta entre } \\
\text { ambas técnicas }\end{array}$} \\
\cline { 2 - 7 } & $\boldsymbol{C E}_{\mathbf{9 5}}$ & $\boldsymbol{E P}_{\mathbf{9 5}}$ & $\boldsymbol{C E}_{\mathbf{9 5}}$ & $\boldsymbol{E P}_{\mathbf{9 5}}$ & $\boldsymbol{C E}_{\mathbf{9 5}}$ & $\boldsymbol{E P}_{\mathbf{9 5}}$ \\
\hline Azul1 & 0.0171 & 0.394 & 0.042 & 0.393 & 0.025 & 0.001 \\
\hline Azul2 & 0.0196 & 0.393 & 0.017 & 0.392 & 0.026 & 0.001 \\
\hline $\begin{array}{c}\text { Diferencia absoluta entre } \\
\text { la misma técnica }\end{array}$ & 0.0025 & .001 & 0.025 & 0.001 & \multicolumn{2}{|c}{-} \\
\hline
\end{tabular}

Como se mencionó con anterioridad, se tomó como referencia los valores obtenidos con el receptor geodésico en ambos métodos; esto debido a que comúnmente los trabajos realizados de índole topógrafo-geodésicos son realizados con este tipo de receptores. En el método relativo estático, el receptor de bajo costo tuvo un desempeño comparable con el receptor geodésico. Sin embargo, para el caso de la técnica PPP, existió una diferencia considerable de $2 \mathrm{~cm}$. Asimismo, la diferencia absoluta entre ambas técnicas es mínima considerando los valores como referencia los obtenidos con el receptor geodésico. En ambos casos, para cuestiones de nivelación GNSS, los valores del EPV son elevados, sin embargo, es posible utilizarlos tomando en cuenta las exigencias del proyecto. Por otro, sin considerar el modelo planteado GGM10, ambos receptores presentan valores precisos para el EPV.

\section{Análisis del posicionamiento puntual preciso y relativo estático en equipo de bajo costo}

Respecto a la normatividad de INEGI, las coordenadas deberán estar en el marco y época oficial de referencia, siendo así el ITRF08 época 2010.0. Al emplear el método de PPP las coordenadas están referidas a la época de las observaciones, en este caso en correspondencia con el ITRF14. Por ello, fue necesario realizar la transformación al ITRF08 época 2010.0 siguiendo el procedimiento oficial. Una vez llevadas las coordenadas a la época oficial, se contrastaron las coordenadas geodésicas obtenidas en modo PPP y relativo estático (Tabla 9-10, respectivamente).

Tabla 9. Coordenadas geodésicas obtenidas mediante PPP expresadas ITRF08 época 2010.0 .

\begin{tabular}{|c|c|c|c|c|c|c|c|}
\hline Vértice & $\boldsymbol{\Phi}$ & $\boldsymbol{\lambda}$ & $\mathbf{H}$ & $\begin{array}{c}\boldsymbol{\sigma}_{\boldsymbol{\varphi}} \\
(\mathbf{m})\end{array}$ & $\begin{array}{c}\boldsymbol{\sigma}_{\boldsymbol{\lambda}} \\
(\mathbf{m})\end{array}$ & $\begin{array}{c}\boldsymbol{\sigma}_{\boldsymbol{h}} \\
(\mathbf{m})\end{array}$ & $\begin{array}{c}\mathbf{h} \\
\text { ortométrica }\end{array}$ \\
\hline Azul1 & $\begin{array}{c}24^{\circ} 48^{\prime} \\
57.41687^{\prime},\end{array}$ & $\begin{array}{c}107^{\circ} 8^{\prime} \\
40.62949^{\prime}\end{array}$ & $\begin{array}{c}130.16 \\
91222\end{array}$ & $\begin{array}{c}0.015 \\
9\end{array}$ & $\begin{array}{c}0.01 \\
83\end{array}$ & $\begin{array}{c}0.01 \\
34\end{array}$ & 157.11 \\
\hline Azul2 & $\begin{array}{c}24^{\circ} 48^{\prime} \\
57^{\circ} .41293\end{array}$ & $\begin{array}{c}107^{\circ} 8^{\prime} \\
40.57007^{\prime}\end{array}$ & $\begin{array}{c}129.12 \\
33141\end{array}$ & 0.005 & $\begin{array}{c}0.00 \\
8\end{array}$ & $\begin{array}{c}0.00 \\
5\end{array}$ & 156.06 \\
\hline $\begin{array}{c}\text { Diferencia } \\
\text { absoluta }\end{array}$ & $\mathbf{0 . 0 0 3 9 4}$ & $\mathbf{0 . 0 5 9 3 3}$ & $\begin{array}{c}\mathbf{1 . 0 4 5 8} \\
\mathbf{0 7 9}\end{array}$ & $\begin{array}{c}\mathbf{0 . 0 1 0} \\
\mathbf{9}\end{array}$ & $\begin{array}{c}\mathbf{0 . 0 1} \\
\mathbf{0 3}\end{array}$ & $\begin{array}{c}\mathbf{0 . 0 0} \\
\mathbf{8 4}\end{array}$ & $\mathbf{1 . 0 5}$ \\
\hline
\end{tabular}


Tabla 10. Coordenadas geodésicas obtenidas mediante relativo estático expresadas ITRF08 época 2010.0.

\begin{tabular}{|c|c|c|c|c|c|c|c|}
\hline Vértice & $\boldsymbol{\varphi}$ & $\boldsymbol{\lambda}$ & $\mathbf{H}$ & $\begin{array}{c}\boldsymbol{\sigma}_{\boldsymbol{\varphi}} \\
(\mathbf{m})\end{array}$ & $\begin{array}{c}\boldsymbol{\sigma}_{\boldsymbol{\lambda}} \\
(\mathbf{m})\end{array}$ & $\begin{array}{c}\boldsymbol{\sigma}_{\boldsymbol{h}} \\
(\mathbf{m})\end{array}$ & $\begin{array}{c}\mathbf{h} \\
\text { ortométrica }\end{array}$ \\
\hline Azul1 & $\begin{array}{c}24^{\circ} 48^{\prime} \\
57.41591^{\prime},\end{array}$ & $\begin{array}{c}107^{\circ} 8 \\
40.61409^{\prime},\end{array}$ & $\begin{array}{c}129.21 \\
61886\end{array}$ & 0.007 & $\begin{array}{c}0.00 \\
7\end{array}$ & $\begin{array}{c}0.01 \\
8\end{array}$ & 159.15 \\
\hline Azul2 & $\begin{array}{c}24^{\circ} 48^{\prime} \\
57.40555^{\prime},\end{array}$ & $\begin{array}{c}107^{\circ} 8 \\
40.59929\end{array}$ & $\begin{array}{c}128.57 \\
01791\end{array}$ & 0.008 & $\begin{array}{c}0.00 \\
6\end{array}$ & $\begin{array}{c}0.01 \\
6\end{array}$ & 155.51 \\
\hline $\begin{array}{c}\text { Diferencia } \\
\text { absoluta }\end{array}$ & $\mathbf{0 . 0 1 0 3 6}$ & $\mathbf{0 . 0 1 4 8}$ & $\begin{array}{c}\mathbf{0 . 6 4 6 0} \\
\mathbf{0 9 5}\end{array}$ & $\mathbf{0 . 0 0 1}$ & $\begin{array}{c}\mathbf{0 . 0 0} \\
\mathbf{1}\end{array}$ & $\begin{array}{c}\mathbf{0 . 0 0} \\
\mathbf{2}\end{array}$ & $\mathbf{3 . 6 4}$ \\
\hline
\end{tabular}

Como es mencionado en secciones anteriores, el tiempo juega un papel clave en la obtención de coordenadas precisas, al igual que los productos satelitales. Con base a esta afirmación, se presenta una alta precisión para el receptor de bajo costo obtenida para la técnica PPP (Tabla 10), ya que, la desviación estándar presentada para la componente horizontal y vertical es de $\approx 1 \mathrm{~cm}$ en un tiempo de observación $>2 \mathrm{~h}$; asimismo, acorde con Choy et al. (2017) es necesario un tiempo de observación de $1 \mathrm{~h}$ para obtener una precisión aproximada de $5 \mathrm{~cm}$, lo cual fue comprobado. Por otro lado, la diferencia absoluta de las coordenadas en $\mathrm{cm}$, existe una diferencia significativa, ya que para la latitud se encuentra en el orden de $12 \mathrm{~cm}$, siendo considerablemente más grande para la longitud donde es $>1 \mathrm{~m}$. No obstante, en cuestión de tiempo, el receptor de bajo costo llevó a cabo observaciones GNSS durante un tiempo mayor a dos horas, en contraste, el receptor geodésico un tiempo menor; donde este último logró una mejor precisión en un menor tiempo. Este hecho, puede estar correlacionado a que la antena utilizada con el receptor de bajo costo no cuenta con parámetros de calibración, no logrando hacer una corrección del centro de fase, además de ser altamente afectado por el efecto de multitrayectoria. Aún con la falta de calibración de la antena, los resultados del método PPP en el equipo de bajo costo, resulta ser aceptado para aplicaciones o trabajos topógrafo-geodésicos.

Para la técnica relativo estático el equipo de bajo costo presenta un desempeño apto al igual que la precisión alcanzada con PPP, siendo más precisa con el relativo estático. Las coordenadas obtenidas, presentan una desviación similar, sin embargo, existe una diferencia de $30 \mathrm{~cm}$ entre las coordenadas obtenidas con el receptor de bajo costo y el receptor geodésico. En este mismo sentido, se prueba la factibilidad de utilizar un receptor de bajo costo en modo relativo estático para líneas base que superan los $30 \mathrm{~km}$.

En cuestión de la altura, se presenta una desviación estándar de un centímetro como máximo, sin embargo, al considerar el modelo GGM10 (conforme a la norma), la altura calculada es afectada, no logrando entrar en los valores recomendados por INEGI para el EPV. Igualmente, es posible usarla de acuerdo con las exigencias del proyecto. La altura ortométrica con 
mayor diferencia es la presentada por el método relativo estático, teniendo una discrepancia de $3.64 \mathrm{~m}$, teniendo un mejor comportamiento mediante la técnica PPP; lo anterior, considerando como referencia el receptor de bajo costo (azul1).

\section{Discusión}

Las coordenadas resultantes para el método relativo estático utilizando el receptor de bajo costo, representa una mejor precisión, esto, considerando la desviación estándar alcanzada. Sin embargo, considerando como referencia el receptor geodésico, se estima una diferencia de $40 \mathrm{~cm}$ en el posicionamiento obtenido. Esta diferencia es significativa, lo cual es recomendable utilizar el receptor de bajo costo para trabajos de posicionamiento y no para control de obras de ingeniería debido a la diferencia presentada considerando que los valores se encuentran lejos de los que son tomados como referencia (los obtenidos por el receptor geodésico).

Por otro lado, tomando en cuenta la técnica PPP, el posicionamiento obtenido (tomando como referencia el receptor geodésico), la diferencia mínima es de $2 \mathrm{~cm}$. En estos términos, la técnica PPP considerando precisiones alcanzadas la hace recomendable para el monitoreo de estructuras como las presentadas en Tang et al. (2017); Vazquez et al. (2017) donde es posible aplicar filtros para encontrar la probabilidad de falla.

Por otro lado, es importante realizar pruebas de calibración y establecimiento de líneas base geodésicas donde la distancia sea comparada con el cálculo con referencia entre dos puntos obtenidos con GNSS y mediciones de distancia con una estación total en modo relativo estático, tomando como base los resultados expuestos por Garrido-Carretero et al. (2019) bajo la técnica RTK.

Para el caso del cálculo de la altura ortométrica conforme a la normatividad de INEGI, resultó que en todos los casos al introducir el modelo GGM10 redujo la precisión alcanzada, esto debido a que cuenta con una precisión de $20 \mathrm{~cm}$. Asimismo, es posible utilizar el receptor de bajo costo sin considerar el modelo, es decir, únicamente con la altura elipsoidal. En este sentido, en ambas técnicas, resultó que es posible alcanzar altas precisiones. Tomando como referencia el receptor geodésico, se presentó una diferencia absoluta $>1$ $\mathrm{m}$, lo cual sigue siendo un reto realizar una nivelación con GNSS con ambos equipos, aun cuando sea tomado como referencia el receptor geodésico.

\section{Conclusiones}

En cuestión del posicionamiento en tiempo real con un receptor de bajo costo, Garrido-Carretero et al. (2019) prueba que es factible utilizar un receptor de bajo costo con una frecuencia, ya que alcanza posicionamiento en el orden del centímetro considerando distancias cortas; determinando que es 
óptimo para agricultura de precisión y aplicaciones catastrales. En este mismo sentido, al probar el equipo de bajo costo de doble frecuencia en modo relativo estático, se confirma que a distancias $\leq 33 \mathrm{~km}$ el equipo de bajo costo es comparable con un receptor de doble frecuencia geodésico, siempre y cuando se considere un tiempo mayor de observación.

Con base en lo anterior, Zamora-Maciel et al. (2020) prueba la factibilidad para el uso de equipos de bajo costo considerando una línea base corta de aproximadamente $10 \mathrm{~km}$ en relativo estático, lo cual muestra que es posible utilizarlos para trabajos topógrafo-geodésicos en distancias cortas; de la misma forma, los resultados presentados confirman que es posible utilizarlos en distancias de aproximadamente $33 \mathrm{~km}$ en este mismo modo.

Evidentemente, sigue siendo un reto encontrar el uso de los receptores geodésicos en cuestiones altimétricas, esto es reflejado de igual forma para los receptores de bajo costo, ya que, la precisión decrece en función del modelo GGM10 implementado conforme a la normatividad. Por otro lado, de no considerar el modelo, los resultados muestran que se pueden obtener precisiones comparables con el receptor geodésico.

En cuestión de tiempo, con el receptor de bajo costo se comprueba lo expuesto por (Choy et al. 2017), necesitando un tiempo $>1 \mathrm{~h}$ para lograr una precisión de $5 \mathrm{~cm}$ considerando los parámetros pertinentes mediante la técnica PPP, pero de igual manera sigue siendo una alternativa óptima a los receptores geodésicos. En este sentido, queda la factibilidad de probar la solución alcanzada por los equipos de bajo costo utilizando la resolución de ambigüedad PPP-AR, lo cual, podría mejorar la solución.

Finalmente, se comprueba que es factible el uso del equipo de bajo costo para aplicaciones topógrafo-geodésicas para trabajos relativos a la componente horizontal, en lo correspondiente a la componente vertical es posible considerar el modelo GGM10 y utilizar el receptor, si y solo si, los requisitos del proyecto lo permitan.

\section{Agradecimientos}

Este trabajo fue realizado fue llevado a cabo mediante el apoyo económico (CVU: 429125 y 817394) del Consejo Nacional de Ciencia y Tecnología (CONACyT) en México.

\section{References:}

1. Alkan, R. M., Ilçi, V., Ozulu, I. M., \& Saka, M. H. (2015). A comparative study for accuracy assessment of PPP technique using GPS and GLONASS in urban areas. Measurement: Journal of the International Measurement Confederation, 69, 1-8. https://doi.org/10.1016/j.measurement.2015.03.012

2. Altamimi, Z., Métivier, L., \& Collilieux, X. (2012). ITRF2008 plate 
motion model. Journal of Geophysical Research: Solid Earth, 117(7), 1-14. https://doi.org/10.1029/2011JB008930

3. Cabral-Cano, E., Pérez-Campos, X., Márquez-Azúa, B., Sergeeva, M. A., Salazar-Tlaczani, L., DeMets, C., ... Miller, M. (2018). TLALOCNet: A continuous GPS-met backbone in Mexico for seismotectonic and atmospheric research. Seismological Research Letters, 89(2A), 373-381. https://doi.org/10.1785/0220170190

4. Cai, C., \& Gao, Y. (2010). Precise Point Positioning Using Combined GPS and GLONASS Observations. Journal of Global Positioning Systems, 6(1), 13-22. https://doi.org/10.5081/jgps.6.1.13

5. Chen, C. Y., Lee, J. C., Chen, Y. G., \& Chen, R. F. (2014). Campaigned GPS on Present-day crustal deformation in northernmost Longitudinal Valley preliminary results, Hualien Taiwan. Terrestrial, Atmospheric and Oceanic Sciences, 25(3), 337-357. https://doi.org/10.3319/TAO.2013.12.25.01(TT)

6. Choy, S., Bisnath, S., \& Rizos, C. (2017). Uncovering common misconceptions in GNSS Precise Point Positioning and its future prospect. GPS Solutions, 21(1), 13-22. https://doi.org/10.1007/s10291-016-0545-X

7. Cina, A., \& Piras, M. (2015). Performance of low-cost GNSS receiver for landslides monitoring: test and results. Geomatics, Natural Hazards and Risk, $6(5-7)$, 497-514. https://doi.org/10.1080/19475705.2014.889046

8. Duong, V., Harima, K., \& Rizos, C. (2020). Multi-frequency MultiGNSS PPP : A Comparison of Two Ambiguity Resolution Methods. (February).

9. Estey, L. H., \& Meertens, C. M. (1999). TEQC: the multi-purpose toolkit for GPS/GLONASS data. GPS Solutions, 3(1), 42-49.

10. Ferhat, G., Malet, J.-P., \& Ulrich, P. (2015). Evaluation of different processing strategies of Continuous GPS (CGPS) observations for landslide monitoring. EGU General Assembly Conference Abstracts, $17,10582$.

11. Garrido-Carretero, M. S., de Lacy-Pérez de los Cobos, M. C., BorqueArancón, M. J., Ruiz-Armenteros, A. M., Moreno-Guerrero, R., \& GilCruz, A. J. (2019). Low-cost GNSS receiver in RTK positioning under the standard ISO-17123-8: A feasible option in geomatics. Measurement: Journal of the International Measurement Confederation, 137, 168-178. https://doi.org/10.1016/j.measurement.2019.01.045

12. Gezgin, C., \& Acar, M. (2016). Investigation of effect of GNSS observation time to baseline solution. International Scientific Conference on Applied Sciences. 
13. Guo, L., Jin, C., \& Liu, G. (2018). Evaluation on measurement performance of low-cost GNSS receivers. 2017 3rd IEEE International Conference on Computer and Communications, ICCC 2017, 10671071. https://doi.org/10.1109/CompComm.2017.8322706

14. Gurtner, W. (1994). INNOVATION: RINEX--THE RECEIVER INDEPENDENT EXCHANGE FORMAT. GPS World, 5(7), 48-53.

15. Herrada, A., Miranda, S., Fuentes, C., Torres Lobato, O., Pintos, H., \& Smalley (Jr), R. (2010). Monitoreo de la calidad de datos GPS continuo: la estacion UNSJ (San Juan, Argentina). Geoacta, 35(1), 5562.

Retrieved

from

http://www.scielo.org.ar/scielo.php?script=sci_abstract\&pid=S185277442010000100006

16. Hofmann-Wellenhof, B., Lichtenegger, H., \& Wasle, E. (2008). GNSS Global Navigation Satellite System GPS, GLONASS, Galileo and more. Springer Wien New York.

17. INEGI. Norma técnica de Estándares de Exactitud Posicional. , (2010).

18. INEGI. (2016). Procesamiento de Datos GPS Considerando Deformaciones del Marco Geodésico en el Tiempo. México.

19. International GNSS Service. (2015). Current IGS Site Guidelines. Retrieved from https://kb.igs.org/hc/en-us/articles/202011433Current-IGS-Site-Guidelines

20. Kamatham, Y. (2018). Estimation, analysis and prediction of multipath error for static GNSS applications. 2018 Conference on Signal Processing And Communication Engineering Systems, SPACES 2018, 62-65. https://doi.org/10.1109/SPACES.2018.8316317

21. Keskin, M., Sekerli, Y. E., \& Kahraman, S. (2017). Performance of two low-cost GPS receivers for ground speed measurement under varying speed conditions. Precision Agriculture, 18(2), 264-277. https://doi.org/10.1007/s11119-016-9453-x

22. Knight, P. J., Bird, C. O., Sinclair, A., \& Plater, A. J. (2020). A lowcost GNSS buoy platform for measuring coastal sea levels. Ocean Engineering, 203,

107198. https://doi.org/10.1016/j.oceaneng.2020.107198

23. Leick, A., Rapoport, L., \& Tatarnikov, D. (2015). GPS satellite surveying. John Wiley \& Sons.

24. Luzum, B., \& Petit, G. (2010). IERS Technical Note; No. 36.

25. Romero-Andrade, R., Zamora-Maciel, A., Uriarte-Adrián, J. de J., Pivot, F., \& Trejo-Soto, M. E. (2019). Comparative analysis of precise point positioning processing technique with GPS low-cost in different technologies with academic software. Measurement, 136, 337-344. https://doi.org/10.1016/j.measurement.2018.12.100

26. Saastamoinen, J. (1973). Contributions to the theory of atmospheric 
refraction. Bulletin Géodésique (1946-1975), 107(1), 13-34.

27. Saunders, J. K., Goldberg, D. E., Haase, J. S., Bock, Y., Offield, D. G., Melgar, D., ... Mattioli, G. S. (2016). Seismogeodesy using GPS and low-cost MEMS accelerometers: Perspectives for earthquake early warning and rapid response. Bulletin of the Seismological Society of America, 106(6), 2469-2489. https://doi.org/10.1785/0120160062

28. Sharma, G., Champati ray, P. K., \& Mohanty, S. (2018). Morphotectonic analysis and GNSS observations for assessment of relative tectonic activity in Alaknanda basin of Garhwal Himalaya, India. Geomorphology, 301, 108-120. https://doi.org/10.1016/j.geomorph.2017.11.002

29. Souto, M. S. (2014). Análisis de calidad y preprocesamiento de datos GNSS de la estación permanente UCOR (Córdoba, Argentina). Revista de La Facultad de Ciencias Exactas, Físicas y Naturales, 1(1), 91. Retrieved from https://revistas.unc.edu.ar/index.php/FCEFyN/article/view/6971

30. Takasu, T. (2013). RTKLIB 2.4.2 Manual. Retrieved from http://www.rtklib.com/prog/manual_2.4.2.pdf\%0Ahttp://www.rtklib. com/rtklib.htm

31. Tang, X., Roberts, G. W., Li, X., \& Hancock, C. M. (2017). Real-time kinematic PPP GPS for structure monitoring applied on the Severn Suspension Bridge, UK. Advances in Space Research, 60(5), 925-937. https://doi.org/10.1016/j.asr.2017.05.010

32. Tomaštík, J., Saloň, Š., \& Piroh, R. (2017). Horizontal accuracy and applicability of smartphone GNSS positioning in forests. Forestry, 90(2), 187-198. https://doi.org/10.1093/forestry/cpw031

33. Tsakiri, M., Sioulis, A., \& Piniotis, G. (2018). The use of low-cost, single-frequency GNSS receivers in mapping surveys. Survey Review, 50(358), 46-56. https://doi.org/10.1080/00396265.2016.1222344

34. Tsakiri, Maria, Sioulis, A., \& Piniotis, G. (2017). Compliance of lowcost, single-frequency GNSS receivers to standards consistent with ISO for control surveying. International Journal of Metrology and Quality Engineering, 8. https://doi.org/10.1051/ijmqe/2017006

35. Vazquez B., G. E., Gaxiola-Camacho, J. R., Bennett, R., GuzmanAcevedo, G. M., \& Gaxiola-Camacho, I. E. (2017). Structural evaluation of dynamic and semi-static displacements of the Juarez Bridge using GPS technology. Measurement, 110, 146-153. https://doi.org/10.1016/j.measurement.2017.06.026

36. Vázquez, G. E., Bennett, R., \& Spinler, J. (2013). Assessment of Pseudorange Multipath at Continuous GPS Stations in Mexico. Positioning, 04(03), 253-265. https://doi.org/10.4236/pos.2013.43025

37. Wang, D., Meng, X., Gao, C., Pan, S., \& Chen, Q. (2017). Multipath 
extraction and mitigation for bridge deformation monitoring using a single-difference model. Advances in Space Research, 60(12), 28822895. https://doi.org/10.1016/j.asr.2017.01.007

38. Xiao, Y., Yao, M. H., Tang, S. H., Liu, H. F., Xing, P. W., \& Zhang, Y. (2020). Data Quality Check and Visual Analysis of Cors Station Based on Anubis Software. ISPRS - International Archives of the Photogrammetry, Remote Sensing and Spatial Information Sciences, XLII-3/W10, 1295-1300. https://doi.org/10.5194/isprs-archives-xlii3-w10-1295-2020

39. Zamora-Maciel, A., Romero-Andrade, R., Moraila-Valenzuela, C. R., \& Pivot, F. (2020). Evaluación de receptores GPS de bajo costo de alta sensibilidad para trabajos geodésicos . Caso de estudio : línea base geodésica Evaluación de receptores GPS de bajo costo de alta sensibilidad para trabajos geodésicos . Caso de estudio : línea base geodé. Ciencia Ergo-Sum, 27, 0-17. 